\title{
Diabetes and oral diseases- A review
}

\author{
Shaik Ali Hassan ${ }^{1 *}$, Francis Pratyusha ${ }^{2}$ \\ ${ }^{1,2}$ Private Practioner, Dept. of Dental, Dr. Francis Maxillofacial and Dental Clinic, India
}

*Corresponding Author: Shaik Ali Hassan

Email: alishaikhassan@gmail.com

\begin{abstract}
Oral disease is a common problem in diabetes mellitus. A few elements influence oral wellbeing including metabolic clutters, for example, Diabetes Mellitus. Diabetes Mellitus has gotten a worldwide scourge and presents numerous intricacies typically corresponding to the degree and term of hyperglycemia. The motivation behind this survey is to feature different investigations concerning Diabetes Mellitus and its latent capacity impacts on oral wellbeing. In this article we will discuss about the oral problems due to diabetes mellitus.
\end{abstract}

Keywords: Diabetes mellitus, Dental caries, Periodontitis, Cytokines.

\section{Introduction}

Diabetes Mellitus happens when the pancreas doesn't create enough insulin or on the other hand, when the body can't successfully utilize the insulin it produces. The general danger of biting the dust among individuals with diabetes is in any event twofold the danger of their friends without diabetes. ${ }^{1}$ The term DM portrays a metabolic issue of numerous etiology described by incessant hyperglycemia with unsettling influences of sugar, fat, and protein digestion coming about because of imperfections in insulin emission, insulin activity, or both. ${ }^{2}$

DM may give trademark manifestations, for example, polydipsia, polyuria, and polyphagia. In its most serious structures, ketoacidosis or a non-ketotic hyperosmolar state may create and prompt daze, trance like state and, without successful treatment, demise. Frequently side effects are not serious, or might be missing, and subsequently hyperglycemia adequate to cause obsessive and utilitarian changes might be available for quite a while before the analysis is made. ${ }^{3}$

The most common oral health problems associated with diabetes are:

1. Periodontal problem.

2. Salivary gland problem.

3. Fungal infections.

4. slow wound healing.

5. Dental caries.

\section{Periodontal problem}

Periodontitis has been alluded to as the 6th complexity of diabetes. Diabetes is accepted to advance periodontitis through an overstated incendiary reaction to the periodontal microflora. The subgingivalmicroflora in patients with periodontitis who have DM by and large is identical to that seen in patients with periodontitis who don't have a conclusion of diabetes. ${ }^{4,5}$

The nearness of bacterial endotoxins, antigens, and other harmfulness factors invigorate the host immunoinflammatory reaction. Neutrophils are enlisted to the site of the contamination to address the pathogenic microbes, which at that point summon a counter acting agent reaction. In progressively safe people, these occasions lead to the advancement of confined reversible aggravation, known as gum disease. In increasingly vulnerable people, elevated levels of proinflammatory known as cytokines, prostanoids, and framework metalloproteinases — will be delivered by the host, prompting connective tissue breakdown and bone digestion changes related with the bone misfortune that is pathognomonic to periodontitis.

Hazard appraisal is significant in light of the fact that it has been perceived that the more hazard factors a patient has, the almost certain the person in question is to build up the ailment. There is frequently in excess of an added substance impact, there is a synergistic impact between these hazard factors. Recognizable proof and thought of these hazard factors is basic to effective periodontal treatment since they can influence the beginning, the pace of movement, and the seriousness of periodontal infection. Likewise, these hazard elements may decide treatment procedures and clarify changeability in the helpful reactions of patients. Hazard factor appraisals can change the manner in which patients are seen by the specialist, prompting a choice procedure dependent on chance. The essential objective of the professional would be hazard decrease. ${ }^{6}$

\section{Salivary gland problems}

Salivary brokenness showing as diminished salivary stream rate and xerostomia has been accounted for in patients with diabetes. It has been indicated that inadequately controlled sort 2 diabetics have a lower invigorated parotid organ stream rate contrasted with all around controlled patients and patients without diabetes. An expansion in salivary pathogens was additionally revealed in these patients. Patients with diabetes for the most part gripe of xerostomia and need to drink all the time. The steady drying of the mouth disturbs the delicate tissues of oral pit, bringing about aggravation and torment. ${ }^{7}$

\section{Fungal infection}

Oral candidiasis is an entrepreneurial disease every now and again brought about by Candida albicans species. Candidal contamination is increasingly pervasive in patients with diabetes particularly in the individuals who smoke, wear 
false teeth, have poor glycaemic control and use steroids and wide range anti-infection agents. Salivary brokenness in diabetics can likewise add to higher danger of oral candidal disease. $^{8}$

\section{Slow wound healing}

Poor delicate tissue recovery and deferred rigid recuperating in patients with diabetes are known difficulties during oral medical procedure. In this way, the administration of patients with diabetes experiencing oral surgeries is increasingly troublesome.

\section{Dental caries}

It is realized that patients with Diabetes Mellitus are vulnerable to periodontal and salivary disarranges (dry mouth), which could expand their danger of growing new and intermittent dental caries. Diminished salivary emission, increment of starch in parotid organ spit, development of oral yeasts, expanded check of Mutans streptococci and lactobacilli are a portion of the components involved to be dependable to incline diabetics to higher rate of dental caries. $^{10}$

\section{Gum disease}

This is an interminable bacterial contamination that influences the gum tissue and bone that bolsters the teeth. Whenever left untreated, gum sickness can bring about abscesses or the total decimation of the tooth's supporting tissues and, eventually, tooth misfortune. Gum malady will in general be progressively extreme among individuals who have diabetes on the grounds that the illness brings down the capacity to battle contamination and eases back mending. A disease causes glucose level to rise, which makes diabetes increasingly hard to control. Forestalling and treating gum infection can help improve glucose control. $^{11}$

\section{Burning in the oral cavity}

Clinician has to analyse issues like consuming mouth or tongue. The consuming might be because of fringe neuropathy, xerostomia, or candidiasis. Great glycemic control may reduce consuming sensation. Reports have shown that clonazepam might be gainful in certain patients with gripe of oral consuming sensation. ${ }^{13}$ Taste aggravations have been accounted for in patients with $\mathrm{DM}^{14}$ yet all specialists have not watched this finding. Perros and colleagues $^{15}$ announced that some diabetic patients have a gentle impedance of the sweet taste sensation. This might be identified with xerostomia or scattered glucose receptors.

\section{Dental Management}

In this the most important is the medical history of patient followed by the schedule of visits, blood glucose monitoring and various protocols followed for the various procedures like invasive and non invasive.

\section{Past medical records}

Before dental treatment, the dental specialist must get a decent clinical history which shows the kind of diabetes endured and recurrence of hypoglycemic scenes or inconveniences. Antidiabetic drugs, doses times of organization, and status of diabetes control ought to be resolved. As indicated by the ongoing accord of the American Diabetes Association (2010), ${ }^{16}$ glycosylated hemoglobin, that is, $\mathrm{HbA} 1 \mathrm{c} \geq 6.5 \%$, a preprandial glycemia of $\geq 126 \mathrm{mg} / \mathrm{dl}$ and a postprandial glycemia $\geq 200 \mathrm{mg} / \mathrm{dl}$ are intriguing analytic estimations of diabetes.

\section{visiting time}

By and large, morning arrangements are prudent since endogenous cortisol levels are commonly higher as of now cortisol expands glucose levels. For patients accepting insulin treatment, arrangements ought to be planned so they donot concur with pinnacles of insulin action, since that is the time of maximal danger of creating hypoglycemia. ${ }^{17}$

\section{Diet to be taken}

On the off chance that the patient skips breakfast inferable from the dental arrangement however stills takes the ordinary portion of insulin, the danger of a hypoglycemic scene is expanded. For specific methodology (e. g., cognizant sedation), the dental specialist may demand that the patients modify their typical eating regimen before the strategy. In such cases, the drug portion may should be adjusted in meeting with patient's doctor.

\section{Blood glucose level reports}

Contingent upon the patient's clinical history, prescription routine and system to be performed, dental specialists may need to gauge the blood glucose level before starting a methodology. This should be possible utilizing financially accessible electronic blood glucose screens, which are moderately modest and have a high level of precision. Patients with low plasma glucose levels $(<70 \mathrm{mg} / \mathrm{dl}$ for the vast majority) ought to be given an oral sugar before treatment to limit the danger of a hypoglycemic occasion. Clinician ought to allude patients with essentially raised blood glucose levels for clinical discussion before performing elective dental techniques. ${ }^{18}$

\section{Type 1 diabetes}

\section{Invasive treatment guidelines}

Very much controlled patients can be dealt with comparatively to nondiabetic people. Know about the expanded vulnerability of these patients to contaminations and deferred wound recuperating. In ineffectively controlled patients, defer the dental treatment if conceivable until they have accomplished great metabolic control. ${ }^{19}$

\section{Invasive treatment guidlines}

Patients ought to approach their primary care physician for directions concerning their medicine (ordinarily, in the event that they have metabolic steadiness, they should take a 
large portion of their day by day portion of insulin the morning of the treatment; at that point, after the intercession, the entire portion ought to be taken with an enhancement of fast acting insulin). Blood glucose ought to be estimated preoperatively. In the event that it is somewhere in the range of 100 and $200 \mathrm{mg} / \mathrm{dl}$, the obtrusive dental system can be performed. In the event that blood glucose is $>200 \mathrm{mg} / \mathrm{dl}$, an intravenous mixture of $10 \%$ dextrose into equal parts typical saline is started, and fast acting insulin is controlled subcutaneously. ${ }^{20}$

\section{Type 2 Diabetes}

\section{Noninvasive dental treatment}

Individuals who control their illness well by diet and exercise require no unique perioperative mediation. As in type 1 diabetic patients, know about their defenselessness to diseases and postponed wound mending. In inadequately controlled patients, defer the dental treatment if conceivable until they have accomplished great metabolic control.

\section{Invasive dental treatment}

Patients ought to approach their primary care physician for guidelines in regards to their drug (typically, those patients being treated with oral hypoglycemic operators should take their ordinary portion toward the beginning of the day and eat their normal eating regimen).

Hypoglycemia is the significant issue that goes up against dental professionals while treating diabetic patients, especially if patients are fasting. The clinical introduction of hypoglycemia is fundamentally the same as hyperglycemia. If all else fails, it ought to be treated as a hypoglycemia. The attributes and treatment. ${ }^{21}$ Hypoglycemia typically shows up because of the pressure experienced previously, during, or after the treatment, and has been appeared to cause a huge increment in perioperative bleakness and mortality. ${ }^{22}$

\section{What has to be done by dentist}

Usage Professional instruction and mindfulness inside the diabetes network should be upgraded before these proposals are probably going to be generally embraced. Medicinal services experts ought to be enabled to clarify the requirement for oral cleanliness and the foundation to their enquiries about gum infection. They ought to know that specific meds (prominently calcium channel blockers, tricyclics) may bring about dry mouth (xerostomia), which is probably going to build the collection of plaque and the danger of oral illnesses. Correspondence among diabetes and oral social insurance experts could encourage this strengthening.

Dental hygienists associated with diabetes care should:

1. Update the customer's clinical history and any adjustments in medicine.

2. Devise a treatment design and build up a modified homecare program.

3. Give counsel on the different kinds of oral consideration items and how to utilize them.
4. Instruct customers on the best method to brush and floss.

5. Provide data and advising on tobacco suspension and dietary measures to help diabetic administration.

\section{Conclusion}

Diabetes Mellitus is an incessant, non-transmittable and endemic illness. Type 2 diabetes is progressively normal around the world. Oral indications and intricacies of this sickness have been perceived as of late as a significant inconvenience. There are a few clinical ramifications from this survey. These incorporate, 1) an absence of consciousness of oral difficulties among the two diabetics and wellbeing suppliers, 2) a comprehension of the manner in which diabetes influences oral wellbeing is fundamental for the two patients and clinicians, accordingly, examine right now be supported, 3) requirement for normal followup of diabetics, 4) the significant job that dental specialists should play in perceiving signs and side effects of diabetes and their oral confusion.

\section{Source of funding}

None.

\section{Conflict of interest}

None.

\section{References}

1. Diabetes - A global threat. Lancet 2009; 373:1735.

2. World Health Organization. Global Prevalence of Diabetes: Estimates for the Year 2000 and Projections for 2030. Geneva: World Health Organization, 2009.

3. Moore PA, Zgibor JC, Dasanayake AP. Diabetes: A growing epidemic of all ages. J Am Dent Assoc 2003;134:11-5.

4. Shelesh J, Swarnlata S. Type 2 diabetes mellitus- Its global prevalence and therapeutic strategies. Diabetes Metab Syndr 2010;4:48-56.

5. Bell G, Large D, Barclay S. Oral Health Care in Diabetes Mellitus. Dent Update 1999;26:322-30.

6. Baldwin E. Oral Health. Lancet 2009;373:628-9.

7. Loe H. Periodontal disease: The sixth complication of diabetes mellitus. Diabetes Care 1993;16:329-34.

8. Preshaw PM. Periodontal disease and diabetes. J Dent 2009;37:575-7.

9. Taylor GW, Borgnakke WS. Periodontal disease: Associations with diabetes, glycaemic control and complications. Oral Dis 2008;14:191-203.

10. Davies RM, Davies GM. Periodontal disease and general health. Dent Update 2005;32:438-42.

11. Dental Hygienists: Your partners in oral health. Available from: www.odha.on.ca [Last accessed on 2014 Mar 18].

12. Quirino MR, Birman EG, Paula CR. Oral manifestation of diabetes mellitus in controlled and uncontrolled patients. Braz Dent J 1995;6:131-6.

13. Moore PA, Guggenheimer J, Etzel KR, Weyant RJ, Orchard T. Type 1 diabetes mellitus, xerostomia, and salivary flow rates. Oral Surg Oral Med Oral Pathol Oral Radiol Endod 2001;92:281-91.

14. Chavez EM, Taylor GM, Borell LN, Ship JA. Salivary function and glycemic control in older persons with diabetes control. Oral Surg Oral Med Oral Pathol Oral Radiol Endod 2000;89:305-11. 
15. Russotto SB. Asymptomatic parotid gland enlargement in diabetes mellitus. Oral Surg Oral Med Oral Pathol 1981;52:594-8.

16. Guggenheimer J, Moore PA, Rossie K, Myers D, Mongelluzzo $\mathrm{MB}$, Block HM, et al. Insulin dependent diabetes mellitus and oral soft tissue pathogenesis, II: Prevalence and characteristics of candida and candidial lesions. Oral Surg Oral Med Oral Pathol Oral Radiol Endod 2000;89:570-6.

17. Hill LV, Tan MH, Periara LH, Embil JA. Association of oral candiasis with diabetic control. J Clin Pathol 1989;42:502-5. 24.

18. Jones AC, Bentsen TY, Freedman PD. Mucormycosis of the oral cavity. Oral Surg Oral Med Oral Pathol 1993;75:455-60.

19. Grushka M, Epstein J, Mott A. An open-label, dose escalation pilot study of the effect of clonazepam in burning mouth syndrome. Oral Surg Oral Med Oral Pathol Oral Radiol Endod 1998;86:557-61.
20. Ship JA. Diabetes and oral health: An overview. J Am Dent Assoc 2003;134:4-10S.

21. Perros P, Mac Farlane TW, Counsell C, Frier BM. Altered taste sensation in newly-diagnosed NIDDM. Diabetes Care 1996;19:768-70.

22. Gutiérrez JL, Bagán JV, Bascones A, Llamas R, Llena J, Morales A, et al. Consensus document on the use of antibiotic prophylaxis in dental surgery and procedures. Med Oral Patol Oral Cir Bucal 2006;11:E188-205.

23. Bergman SA. Per ioperative management of the diabetic patient. Oral Surg Oral Med Oral Pathol Oral Radiol Endod 2007;103:731-7.

How to cite: Hassan SA, Pratyusha F, Diabetes and oral diseases- A review. IP J Nutr Metab Health Sci 2020;3(1):69. 